\section{Sobre el fortalecimiento en la comunidad}

\section{Santiago de Cali, noviembre 30 de 2016.}

\section{Por: Laura Tamayo Cortés \\ Estudiante de Psicología y Comunicación \\ Pontificia Universidad Javeriana \\ Cali, Colombia}

E-mail: lataco@javerianacali.edu.co

Quiero iniciar este texto haciendo una confesión importante: no tenía ni idea de cómo escribirle una carta a la ganadora del premio de la Sociedad Interamericana de Psicología en 1995 y del Premio Nacional de Ciencias en el área de ciencias sociales, en Venezuela en el 2000. Es decir, a usted, apreciada profesora Maritza Montero, a quien conozco a través de lecturas, profesores y algunos videos de YouTube. Primero, pensé en escribirle un texto muy formal, con todo el protocolo que me han enseńado y que una licenciada en Psicología con un Magíster en Psicología y un Doctorado en Sociología se merece tener entre sus manos, pero no fue así. Continué pensando y llegué a la conclusión de que si usted algún día leyera mis letras me encantaría que por este medio conociera un poco lo que soy y el impacto que han tenido sus construcciones en mí.

Este semestre 2016-2, el cual apenas estamos terminando después de muchos trasnochos, parciales, proyectos que sacan canas y con el único anhelo de que llegue la Navidad, tuve la oportunidad de matricular una de las asignaturas que más le han dado sentido a mi vida estudiantil: Psicología Social II. En una de las clases estudiamos su texto titulado El fortalecimiento en la comunidad, sus dificultades y alcances. Admito que cuando lo leí, debido quizás a la falta de detalle que algunas veces me caracteriza, lo único que me llamó la atención fue su definición de fortalecimiento, la que subrayé y le tomé una foto con mi celular. Sin embargo, cuando la profesora con voz y ojos entusiastas empezó a hablar de su vida, obra y del tema del fortalecimiento, mi mirada cambió completamente.

Fue sorprendente conocer que una mujer nacida y criada en un contexto histórico difícil tenga una fuerte pasión por las comunidades, al punto de pensar en la importancia de la creación de una psicología crítica que trate y solucione problemas desde la perspectiva latinoamericana. A medida que escuchaba este discurso, la definición que me cautivó tomaba sentido, pues ahora conocía que su interés primordial son los procesos de transformación de las sociedades, dándoles así un lugar y una voz a las personas en condiciones de vulnerabilidad, por medio de intervenciones que hagan que las comunida-

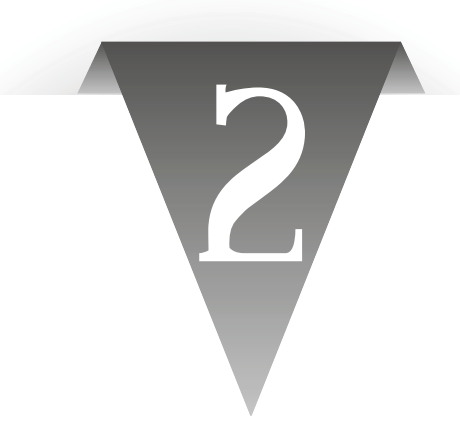

Ganador segundo puesto

des participen, tomen consciencia, control y poder de sus problemáticas, se comprometan, sean seres políticamente activos y autónomos, desarrollen habilidades y creen su propia identidad social.

Salí de esa clase convencida de tres aspectos: primero, que las comunidades son las que poseen el poder para transformar su realidad; segundo, que se debe combatir la desesperanza aprendida; y tercero, que formo parte de un país que se encuentra en un momento coyuntural y que debo poner mi conocimiento al servicio de todas sus necesidades.

Por esto y para empezar a construir una sociedad colombiana más política, he intentado ser una voz que da aliento a las personas de mi alrededor, especialmente a los grupos universitarios a los que pertenezco, los cuales están relacionados con los temas de liderazgo, espiritualidad y trabajo en equipo y en comunidades, pues en algunas ocasiones se presentan situaciones que reflejan la transmisión de un pensamiento negativo y pesimista. Asimismo, en mi carrera y en el centro pastoral de la universidad he ayudado a dirigir y a diseñar talleres en los que se han discutido y reflexionado sobre la importancia de estar atento a la comunidad, leer sus necesidades y actuar o reformular a partir de ellas y no según lo que nosotros pensemos que es mejor.

Finalmente, me gustaría contarle que el próximo semestre tengo un reto grandísimo, pues en Psicología Social III unas compañeras y yo estaremos interviniendo en una fundación de niños con cáncer. Siento un poco de miedo por lo que pueda pasar, pero también me emocionan las maravillas que podremos realizar si miramos con sus mismos ojos de respeto, comprensión y paciencia a este proceso de transformación bidireccional. Solo agradezco por todas las enseñanzas que desde lejos tengo de usted y por la sabiduría que día a día transmite a las generaciones venideras para que la psicología sea cada día una disciplina más humana.

Me despido con la ilusión de ser recordada por usted. 